\section{Quality of the practice-oriented education and adaptations of fashion disciplines by video conference during the COVID-19 pandemic}

\author{
Felipe Guimarães Fleury de Oliveira ${ }^{a}$ \\ Mirtes Maris de Oliveira ${ }^{b}$
}

Universidade Anhembi Morumbi

The new Coronavirus pandemic has led Universidade Anhembi Morumbi undergraduate courses in Fashion Design and Fashion Business to maintain the educational activities of students, offering remote synchronous classes by video conference through the Blackboard Collaborate Ultra tool. As the educational system was forced to migrate to the online environment, teachers found themselves challenged to deal with distance learning in online classrooms, aiming to reduce the distance, both physical and mental, and increase interactivity and communication with students, demonstrating pedagogical skills in their managerial role, and even providing technical support.

Despite the challenges, teachers had to effectively facilitate teaching- learning through remote, synchronous video conferencing classes, while maintaining the experience of authentic, high-quality learning in which concerns student satisfaction rates.

The referred article is a partial result of an ongoing research, which aims to assess the quality of practice-oriented teaching based on the case study of the Textile Technology and Surface Design courses by video conference during the COVID-19 pandemic.

Given the uncertainties of educational quality through this videoconferencing tool and the challenge of migrating to an online environment, new strategies have given base for preparing class material through graphic resources to ensure that the learning objectives were achieved.

The theoretical-practical activities of the two courses investigated - physicalchemical analysis of textile fibers, fundamental ligaments, handloom, and stamping module - were adapted so that students could perform them without using or requesting any specific technical material.
Based on a theoretical reference survey of active methodologies, with a view to the impact of the case study of the courses being analyzed and the relevance of the research focused on teaching-learning, an exploratory-descriptive survey is being carried out. Data shall be collected from students who have been organized in two groups, being 126 students from the Textile Technology course and 72 students from the Surface Design course, totaling 198 students. The frequency of students in each video conference is being monitored and the percentage of attendance must be equal to or greater than $90 \%$, minimum. Of the 198 students, 155 students have had a presence equal to or above $90 \%$ and, of the 155 students, 128 have responded to the survey so far.

Preliminary results show that $82 \%$ of the students interviewed were very satisfied with the quality of teaching-learning of the Textile Technology and Surface Design courses by video conference through the Blackboard Collaborate Ultra tool.

The still ongoing research has revealed a positive result of the experience for the student: the quality of teaching-learning depends on the cognitive and social presence, not on technology. One may consider that the research has some limitations, as it comprehends a small group of students. Therefore, inferences cannot yet be made about other courses or faculty. Retention or approval rates have not yet been considered, since $98 \%$ of students have completed the subjects and been approved.

KEYWORDS

Fashion Design, Practice-Oriented, Distance Education, Active Methodology 